\title{
Knowledge Management framework for the supervision of IT postgraduate research in Sri Lanka
}

\author{
W.M.J.H. Fernando \\ Faculty of Graduate Studies and Research, \\ Sri Lanka Institute of Information Technology, \\ Malabe, Sri Lanka \\ jeewafdo91@yahoo.com
}

\author{
M.P.A.W. Gamage \\ Faculty of Computing, \\ Sri Lanka Institute of Information Technology, \\ Malabe, Sri Lanka \\ anjalie.g@sliit.lk
}

\begin{abstract}
The private sector higher education industry is increasingly attracting a knowledge-based community that depends critically on Knowledge Management (KM) and Knowledge Sharing (KS) activities to expand the quality of supervising postgraduate research students. Using the KM approach to share good research supervision knowledge will help junior research supervisors to conduct quality research with students and thereby help the supervision process to be more successful. The objective of this study is to suggest a conceptual framework that fits in the supervision process. This is conducted to investigate how KM and Information Technology (IT) can be used to develop a model for the supervision process. The framework highlights the critical KM activities in the research supervision process, and it is based on the Task/Technology Fit theory. Using this framework, the knowledge of the more experienced supervisors will be captured and used by junior supervisors in their supervision process.
\end{abstract}

Keywords- Knowledge Management, Postgraduate Research, Task / Technology Fit Theory, Information Technology \& Conceptual Framework

\section{INTRODUCTION}

In the present world of knowledge revolution, knowledge has been passed down to generation by generation. S. H. M. Amin [1] has pointed out that knowledge is a critical component of global competitiveness. It supports nurturing knowledge sharing mechanisms and learning abilities in and out of the workplace. Understanding the status of knowledge as an important element in universities that look after knowledge sharing mechanisms and learning skills within an organization and across organizations.

$\mathrm{KS}$ is a major component of KM and its strategies are the solutions to structural and individual progress. It is mainly defined as the method of distributing information and knowledge within the workplace [2]. The method of exchanging and shifting existing knowledge and ideas among postgraduate research students create new knowledge and ideas to help higher education institutions to reach their objectives. This aims to provide a better communication link between the students and the supervisor and helps to align and complete research work in the field of IT more successfully. The findings from this study will bring advantages to IT postgraduate research supervision. The KM system (KMS) attempts to integrate the relevant information technology into the research supervision process that would support supervisors' knowledge creation, knowledge sharing, applications, and knowledge management. The proposed framework would assist the institutions in higher education to identify the critical KM activities associated with the KM Technology and plan for the postgraduate research supervision KMS for the supervision process.
Education can be measured as one of the most important effective investments that are involved all the time. Learning through lifetime helps to search, protect, and broadcast knowledge. There is a close relationship in the fundamental roles between education in higher education institutions and KM. Excelling in higher education is about changing students, and universities should provide students with a transformative learning environment. The problem identified is that Postgraduate research studies are challenging and sometimes students may experience problems making progress. Currently, Sri Lankan private sector education institutions face a lot of problems during their postgraduate research supervision and in their profession, which requires more attraction for management. Some of these challenges consist of miscommunication among project supervisors and students, ambiguities in research doings, and lack of effecting the following processes for the position of different research work. Top management at the institutions must play their role and put more effort to ensure that their project supervisors have the proper platform and support to share their knowledge among students.

Mainly this study focuses on state universities and private higher education institutions in Sri Lanka. Currently, state universities rank higher in postgraduate research than the private institutions and the research supervision process is in a standard level. It was noted that, KM can be used to increase the ability of private higher education institutions to reach their targets by using and sharing knowledge in different ways which progress to success as a team. Part of $\mathrm{KS}$ with relative to individual performance among research students is to accomplish excellent supervising and learning methods. This also provides standard education and postgraduate qualification which are required by the staff. $\mathrm{KS}$ is also a vital component when it comes to achieving the vision \& missions of private higher educational institutions.

\section{LITERATUR REVIEW}

Higher education institutions of Sri Lanka under the private sector are registered under the company act. They provide IT undergraduate degrees, limited postgraduate degrees, and MPhil and Ph.D. programs [3]. Some even offer postgraduate degree programs of foreign universities [4].

The main role of private education is generating and moving valuable knowledge among the followers itself to make them competent [5]. Currently, private higher education institutes have several years of experience in their academic work where many professors are employed in their institutes. The main objective of this research is to suggest a conceptual framework that fits in the supervision process, using KM activities and IT for designing such a model for supervision [6]. The main aim is to provide a better 
communication link between the students and the supervisor and help to align and complete research work in the field of IT more successfully. It is often evident that junior supervisors and students face difficulties in initiating research activities. The differences among supervisors and students' stages of knowledge and skills augment the problems in the research supervision process [7].

Research is a communicating process and needs the development of social as well as theoretical skills. A school's managerial function is normally taken to means as referring to handling, operating, or directing an institute to help students towards the accomplishment of Master qualification. Graduate student sometimes has previous knowledge and problems in their research project [3]. As a result, this requires the effective use of resources in research and supervision. Developing skills for effective research supervision are essentials to be engaged in various ways [6].

Swanson \& Watt [3] show theoretical guidelines for research supervision. This theoretical guideline aims to help supervisors in research development to make effective monitoring of research supervision [8]. This work shows that lifelong learning and lifelong research are created on the main 4 stand framework of leaning.

- Learning to know.

- Learning to do.

- Learning to live with others.

- Learning to do.

Yew \& Ahmad [9] state that research supervisors' performances are progressively being determined in the form of education experts' procedures and protocols that drive supervision service distribution. Project supervisors specifically use the research supervision knowledge that joins with their know-how and experience to carry supervision services to supervision.

According to previous works, there is no clear analysis of the processes of postgraduate research supervision planned by researchers to plan the supervision activity based on a dynamic process rather than a static process. They propose various methods and systems to manage supervision activities.

Gatfield and Alpert [10] have proposed the supervisory management styles (SMS), model. It recommends a fourquadrant supervisory style management grid that emphasizes the understanding of supervisory styles and adjustments in the supervisory style during the supervisory phase. The authors have said that supervisors tended to think that they knew which parts of the supervisory process and management styles were more suitable for success. This SMS model highlights the following things:

- Supervisor's help

- Managing skills of students to handle research and their ability to communicate and work together.

De Beer and Mason [11] have proposed the blended postgraduate supervision (BPS) model and is offered in three styles through the classroom, the virtual classroom, and online courses. They have shown that postgraduate supervision is blended learning in these delivery methods, with the exclusion that there is hardly any classroom education but rather face-to-face communication between supervisors and students. The core thing is to offer students with links on web pages that agree with students to access several topics either through the internet or Web CT. This is a chance for students to discuss matters and consult with their project supervisor and use different kinds of technologies to make and share information. Research is a significant method for learning for postgraduate students. It allows them to improve their experiences and range the limits of their knowledge. The practice of IT-based communication, social media, online databases, and elearning systems can expand their skill to detention, transmission, and share information.[11] The BPS shows the supervisors to signify the key foundations of information to be retrieved by students in face-to-face discussions and via the Internet and libraries and assess what the postgraduate student has gained from it. Therefore, the BPS model highlights the following facts:

- Using web technology

- Using IT-based communication

- Supervisor's support

The KM model for the supervision process is a better model that applies to detect the knowledge-sharing impact factors since it is just a research supervision model that is specifically designed for KM and KS. Using this method, one can select the factors which are specific to the research supervision environment. This model has been suggested by Zhao [12]. According to that students to graduate successfully, the supervisory process is very important. The method is complicated and subtle.

A systematic knowledge-sharing approach is required to help both supervisors and students to achieve, share, and apply knowledge. A knowledge-sharing method proposed by Zhao [12] shows that the supervisor focuses on helping students to improve the knowledge-sharing capability in research supervision. This knowledge-sharing capability means not only to the expertise of using enhanced technological resources to manage the information but also to the potential to decide about choosing and using the information. Additionally, Zhao has insisted that postgraduate supervision involves KM and thought that the effectiveness of supervision can be improved by incorporating its concepts.

$\mathrm{KM}$ is an educational benefit and financial resource that supports the quality of a university and operates the research supervision as acquiring knowledge to add benefit to the university. It is also a measurement to evaluate the quality of academic work of a specific university. The entire process of education occurs when people share their knowledge because knowledge is built into the minds of individuals. The important success tips of knowledge sharing are highlighted as a fact in Zhao's KM model.

\section{Methodology}

This research is conducted as a authors' quantitative research. It is based on the authors' collection of data-based theories, hypotheses, and experiments. It is followed by descriptive and inferential statistical methods. According to the nature of the analytical research, it is extended to a descriptive approach to explaining the way something that has happened or happening. 


\section{A. Scope of study}

This study is mainly focusing on state and private sector higher education institutions, under the Sri Lanka University Grant Commission. The targeted participants are the project supervisors in the Faculty of Graduate Studies. The research aims to provide a better communication link between the students and the supervisors and help to align and complete research work in the field of IT more successfully. The findings from this study will bring advantage to the supervision of IT postgraduate research. This study helps to cultivate and justify a framework that helps to examine the project supervisor's behavior towards KM and KS with students. The outcome of this research will be a framework for proper project supervision which can be applied for IT postgraduate research supervision.

\section{B. The study population and sample}

This study focuses only on the IT postgraduate degree programs offered at state and non-state universities. There are six state universities and approximately ten non-state universities in Sri Lanka. According to statistics of IT postgraduate research, the staff population of these state universities is nearly 300 under the categories of academics. According to the statistics of each private university, it consists of approximately 60 staff under the categories of academics in one university. Therefore, the total staff of all the non-state universities is nearly 300 . This study, the target population is 300 . The sample population was taken from 07 universities, 02 state, and 05 non-state universities.

The purposive sample was applied to examine the hypotheses of this study. In the end, researchers made a verdict of the study depending on the chosen sample. Therefor sample required to be accepted base on the aimed population. The findings can be generalized based on selected received samples.

The existing study comprised of 277 responses within seven (both state and non-states) universities. In compliance with the current study selected state university respondents $(40 \%)$ were the University of Moratuwa and University of Colombo. Chosen non-state university respondents $(60 \%)$ were SLIIT, APIIT, ESoft, IIT \& ICBT campus.

\section{Conceptual framework}

This research proposes that KM can be used to increase the ability of private higher education institutions to reach and use supervisor perception and organizational culture in different ways which progress to success.

The conceptual framework for this research is to design from the above literature review. It includes two fields such as independent variables and the dependent variable.

Independent Variables

- The ability of a supervisor to share knowledge.

- Culture of university.

- Supervisor support.

- Learning strategy.

- IT system.

\section{Dependent Variable}

- Quality postgraduate research supervision.

\section{Proposed hypotheses}

- A supervisor's ability to share positively affects KS in quality IT postgraduate research supervision.

- The culture of a university has an important and positive effect on KS in quality IT postgraduate research supervision.

- Supervisor support positively effects in KS in quality IT postgraduate research supervision.

- The learning strategy has an important and positive effect in $\mathrm{KS}$ in quality IT postgraduate research supervision.

- IT system has an important and positive effect in KS in quality IT postgraduate research supervision.

\section{DISCUSSION AND FINDINGS OF THE RESEARCH}

This study is done to develop a KM framework for supervision of IT postgraduate research in Sri Lankan higher education institutions who play an essential role in the academic industry. Mainly the supervision process, Knowledge Management (KM) activities, and technologies are the elements investigated in the research.

This aims to provide a better communication link between the students and the supervisor and help to align and complete research work in the field of IT more successfully. The findings from this study will bring advantage to the supervision of IT postgraduate research. This study helps to cultivate and justify a framework that helps to examine the project supervisor's behavior towards KM and KS with students. The outcome of this research is a framework for quality project supervision which can be applied for IT postgraduate research supervision.

\section{A. Findings of the study}

The general objective of the study is to identify the sources of quality supervision IT postgraduation research supervision. The multiple regression analysis was used to determine whether the ability of a supervisor to share knowledge, the culture of a university, supervisor support, and IT system they use for quality research supervision in Sri Lanka. The results from the regression analysis are presented in Table 1.

TABLE I. THE RESULTS FROM REGRESSION ANAYSIS

\begin{tabular}{|c|c|c|c|c|c|}
\hline \multirow[t]{2}{*}{ Model } & \multicolumn{2}{|c|}{$\begin{array}{c}\text { Unstandardized } \\
\text { Coefficients }\end{array}$} & $\begin{array}{c}\text { Standardized } \\
\text { Coefficients }\end{array}$ & \multirow[t]{2}{*}{$\mathbf{t}$} & \multirow[t]{2}{*}{ Sig. } \\
\hline & B & $\begin{array}{l}\text { Std. } \\
\text { Error }\end{array}$ & Beta & & \\
\hline (Constant) & .027 & .103 & & .267 & .790 \\
\hline SSK & .281 & .056 & .280 & 5.074 & .000 \\
\hline $\mathrm{CU}$ & .184 & .093 & .205 & 1.980 & .050 \\
\hline SS & .741 & .086 & .692 & 8.600 & .000 \\
\hline LSU & .004 & .047 & .005 & .082 & .935 \\
\hline ITS & .200 & .077 & .173 & 2.602 & .010 \\
\hline
\end{tabular}


Table I presents the results of is SPSS linear regression output. The p-value for the ability of the supervisor to share knowledge, the culture of a university, supervisor support, and IT system is less than 0.05 . Hence quality postgraduate research supervision of the research supervisors depends on the ability of supervisors to share knowledge, the culture of a university, supervisor support, and IT system. The R-square value was $0.889(\mathrm{~F}=85.694, \mathrm{p}<0.05)$, which means $9.665 \%$ of the variation in quality postgraduate research supervision can be explained by the ability of the supervisor to share knowledge, the culture of a university, supervisor support and IT system identified in this study.

The VIF values are less than 5. As Denis [13] mentioned if VIF for one of the variables is around or greater than 5, there is multicollinearity associated with that variable. Hence there is no problem of multicollinearity in this model. The Durbin-Watson (DW) statistic should fall within the acceptance range from 1.53 to 2.50 to ensure that there is no autocorrelation problem in the data [14]. The DW statistics of the model is 2.145 , where values around 2 indicate no problem of autocorrelation. In residual diagnostics, the residuals were independent and normally distributed. Between the culture of university and supervisor support, resources recorded the highest beta value (beta $=0.741, \mathrm{p}<$ 0.05). As a conclusion, the result of multiple regression analysis is supported by the data: H1 (A supervisor ability to share positively effects $\mathrm{KS}$ in quality IT postgraduate research supervision.), H2 (The culture of a university has an important and positive effect in $\mathrm{KS}$ in quality IT postgraduate research supervision.), H3 (Supervisor support positive effect in $\mathrm{KS}$ in IT postgraduate research supervision.) and H4 (IT system have important and positive effect in KS in quality IT postgraduate research supervision.).

Taking a deeper look, the effects of the ability of the supervisor to share knowledge, culture of a university, supervisor support, and IT system on quality postgraduate research supervision were identified separately using stepwise regression analysis. The R-square value of the model indicated that $79 \%$ of the variability in quality research supervision. The R-value of the model indicated that $88 \%$ of the variability in quality postgraduate research supervision explained by the ability of the supervisor to share knowledge, the culture of a university, supervisor support, and IT system.

The overall results of the multiple regression analysis and the study hypotheses were presented in Table II illustrating the direct effect model of the study.

TABLE II. HYPOTHESES RESULTS OF MULTIPLE REGRESSION MODEL

\begin{tabular}{|l|l|}
\hline \multicolumn{1}{|c|}{ Hypotheses } & Result \\
\hline $\begin{array}{l}\text { A supervisor's ability to share positively effects KS in } \\
\text { quality IT postgraduate research supervision. }\end{array}$ & Supported \\
\hline $\begin{array}{l}\text { The culture of a university has an important and } \\
\text { positive effect on KS in quality IT postgraduate } \\
\text { research supervision. }\end{array}$ & Supported \\
\hline $\begin{array}{l}\text { Supervisors support positive effect in KS in quality IT } \\
\text { postgraduate research supervision. }\end{array}$ & Supported \\
\hline $\begin{array}{l}\text { The learning strategy has an important and positive } \\
\text { effect in KS in quality IT postgraduate research } \\
\text { supervision. }\end{array}$ & $\begin{array}{l}\text { Not } \\
\text { Supported }\end{array}$ \\
\hline $\begin{array}{l}\text { IT systems have an important and positive effect in KS } \\
\text { in quality IT postgraduate research supervision. }\end{array}$ & Supported \\
\hline
\end{tabular}

\section{B. Discussion}

The proposed framework highlights the critical KM activities in the research supervision process, and it is based on the Task/Technology Fit theory. Using this framework, the knowledge of the more experienced supervisors will be captured and used by junior supervisors in their supervision process.

According to Lin [15], quality research supervision depends on knowledge sharing and the skill of the research supervisor. The study resulted based on several factors of the outcome. Among which it identified different research supervision improvement factors for quality research supervision.

This study integrates perspective from the ability of the supervisor to share knowledge, the culture of a university, supervisor support, the learning strategy, and IT system to propose a suitable framework to identify the factors influencing to improve quality of IT postgraduate research supervision to private higher education institutions in Sri Lanka. The study is based on the Task/Technology Fit theory which has primarily focused on individual performance and the skills of the IT level. Supported by the practical indications this study originates that factors settings have the most significant influence of the university culture and way that they help students to complete their research work. Among the above factors the ability of the supervisor to share knowledge, culture of a university, supervisor support, and IT system has also made a positive impact on quality research supervision. The findings of this study are based on data collected from state and non-state universities in Sri Lanka.

\section{Proposed framework}

Private sector higher education institutions are progressively attracting knowledge-based society which varies critically on $\mathrm{KM}$ and $\mathrm{KS}$ actions to increase the excellence in supervising postgraduate research students.

Expanding the KM approach to share quality research supervision knowledge will help junior research supervisors to conduct quality research with students and thereby help the supervision process to be more successful.

According to the suggested framework for KM in the IT postgraduate research supervision, it introduces the research supervision process with a few inputs,

1) Research student

2) Research environment

3) Supervisor and students' tacit knowledge

4) Library facilities (E-learning \& online database, other IT system)

Apart from the above the framework also identifies the following outputs,

1) Knowledge transformer

2) IT research thesis

3) IT research product

4) Supervisors' and students' explicit knowledge.

5) New technology 
6) Completeness of research thesis and student satisfaction

The study process has a few steps such as defining the research problem and developing research methodology. Throughout this process, the tacit knowledge of students and supervisors is transformed into explicit knowledge and a study on the product and theory is being produced. KM and $\mathrm{KS}$ actions increase the excellence of postgraduate research supervising students. Knowledge Sharing (KS) plays a significant role in this process as it helps and expands the process by improving the quality of IT postgraduate research supervision. The identified factor are listed below,

1) Ensure to give a clear-cut project.

2) Identify students research abilities and carefully assess their needs.

3) Found reasonable, agreed expectation.

4) Work with students and carefully give instruction to conducting research.

5) Encourage the student to complete writing early.

6) Initiate frequent meeting and gives quality feedback.

7) Stimulation and motivation.

8) Support during an academic or personal crisis.

9) Increase the student research interest for their future career.

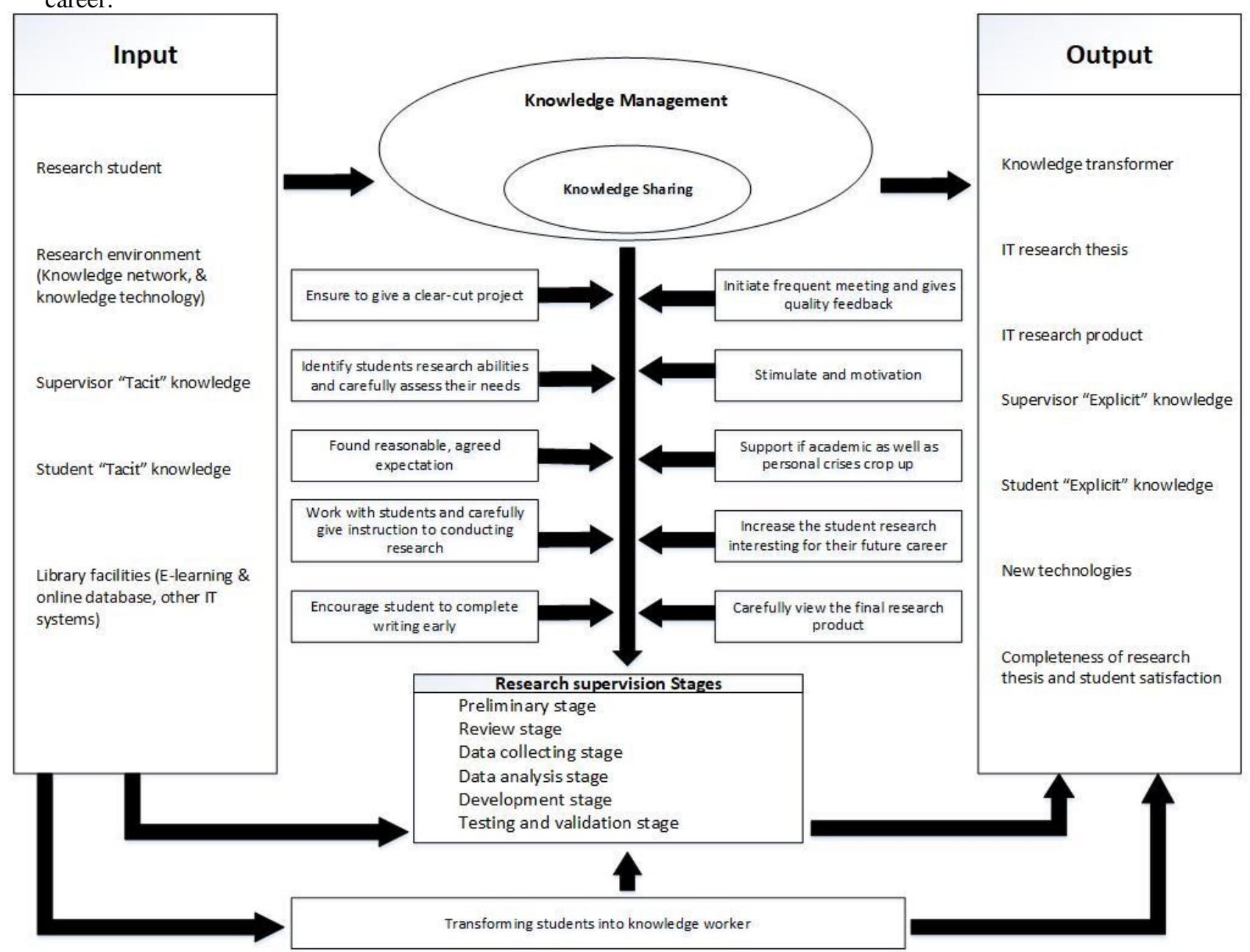

10) Carefully view the final research product

Depending on the framework, the organizational, individual, and technological factors influence the sharing of knowledge into this process.

This factor aims to help supervisors in research supervision to make effective monitoring and management of supervision. According to the framework, the following process stages are needed to be followed by supervisors.

1) Preliminary stage.

2) Review stage.

3) Data collecting stage.

4) Data analysis stage.

5) Testing and validation stage.

This framework is tested by research supervisors of private universities and final year research students in Sri Lanka. One point that they have mentioned in the feedback was impenetrability measuring individual knowledge level. The main reason they emphasize was that there is no correct mechanism to measure current junior supervisors' knowledge and skills of private higher education institutions. By improving the quality of IT postgraduate research supervision in private higher education institutions, the rank of the institutes, and the demand for their degree programs can be increased. 


\section{RESULTS}

In this study, the factors and requirements were gathered by using standard techniques. It has carefully analyzed the gathered data using several methods. Requirements' prioritization methods were used to categorize and give the prioritization for requirements. Also, it analyzes whether there are trends and patterns in the requirements. It also checks if there is a statistical equivalence in the questionnaires which was taken from the users. By using these standard techniques for validating requirements, as a result it comes up with a requirement specification with expected changing requirements in the future.

The developed framework as a result of the study was evaluated to check its validity. In the validation process, it considered taking the finished framework and assessed it for aspects of the usability, and consisted with carry out experiments after implementation, and the feedback was taken to find how far the framework is successful. Here online questionnaires were distributed among a selected group of students to verify developed framework which applies to the IT postgraduate research process. The framework diagram was distributed with the questionnaires. The sample student group size was 130 . The $83 \%$ student very much liked the final framework and features. Here it is conducted to mainly get the responses from the students about the quality research supervision of the proposed framework.

\section{CONCUSION AND FUTURE WORK}

This research help university and postgraduate research supervisors to realize which factors are important for knowledge sharing in the research supervision process. Also, it shows the way that supervisors improve their performance and the way to increase the quality of the research supervision process. Mainly this research is focused on effective KS that can increase the performances, productivity, and usefulness in the postgraduate research supervision process. It helps to improve inventions in private sector higher education institutions. The main objective of the KS approach for postgraduate research supervision is to increase the equality of the postgraduate research training, through the students' knowledge and research experience in the revolution. In the university, KS helps in reducing the cost and is a cheaper path to conduct postgraduate research. It helps the student to complete their MSc degree program within a given period without delays. The outcomes of this study could encourage the university higher management to give structures that would encourage students and research supervisors to share their knowledge. This encouragement may come in the form of incentives, identifications, rank, or development of the university.

This research was conducted only for postgraduate research supervision on the state and non-state universities in Sri Lanka. The discovered result outcomes were found by collecting data gathered by selected seven universities and 120 research supervisors.

Therefore, it is recommended that these statistics of this study can be applied against evaluating related trends in a wider context, like in evaluating quality postgraduate research supervision of any higher education institutions.

In this study, each of the KS effect aspects that fit from the literature for the proposed framework was from several iterative factors that were applied in various areas. The proposed study framework investigates these precursor factors in new areas. The proposed framework in this research can be applied to more universities with various cultures. In the research supervision domain individual, organizational technological factors are very important on $\mathrm{KS}$ in the university environment. But it is recommended that future work should review not only the impact of KS factors (individual, organization technological). but it can also review the impact of $\mathrm{KS}$ on the excellence of both experiences of learning and research stages. The results of such an analysis might improve the achievement rate of students and encourage critical thinking.

\section{REFERENCES}

[1] S. H. M. Amin, A. A. Zawawi, and H. Timan, "To share or not to share knowledge: Observing the factors," in 2011 IEEE Colloquium on Humanities, Science and Engineering, Penang, Malaysia, Dec. 2011, pp. 860-864, doi: 10.1109/CHUSER.2011.6163859.

[2] I. M. Dooba, A. G. Downe, and A. K. Mahmood, "If professors knew what professors know: A technique for capturing university teachers' tacit knowledge of research supervision," in 2010 International Symposium on Information Technology, Jun. 2010, vol. 1, pp. 1-5, doi: 10.1109/ITSIM.2010.5563117.

[3] F. A. Phang, N. H. Sarmin, S. N. A. Zamri, and N. Salim, "Postgraduate Supervision: Supervisors versus Students," in 2014 International Conference on Teaching and Learning in Computing and Engineering, Kuching, Malaysia, Apr. 2014, pp. 251-255, doi: 10.1109/LaTiCE.2014.55.

[4] SRI LANKA QUALIFICATIONS FRAMEWORK.

[5] D. Sheng, L. Qingli, and S. Liang, "Study on improving the service level of engineering supervision of China," in 20107 th International Conference on Service Systems and Service Management, Tokyo, Japan, Jun. 2010, pp. 1-4, doi: 10.1109/ICSSSM.2010.5530125.

[6] O. A. Jassim, M. A. Mahmoud, and M. S. Ahmad, "A Framework for Research Supervision," p. 10, 2015.

[7] H. Jamal, A. Shanaah, and A. Wingkvist, "The Role of Learning Management Systems in Educational Environments: An Exploratory Case Study," p. 67.

[8] J. T. Lubega and M. Niyitegeka, "Integrating E-Supervision in Higher Educational Learning," p. 8.

[9] K.-T. Yew, W. F. W. Ahmad, and J. Jaafar, "A framework for designing postgraduate research supervision knowledge management systems," in 2011 National Postgraduate Conference, Sep. 2011, pp. 1-6, doi: 10.1109/NatPC.2011.6136310.

[10] T. Gatfield and F. Alpert, "The supervisory management styles model," p. 11

[11] D. Maor and J. K. Currie, "The use of technology in postgraduate supervision pedagogy in two Australian universities," Int. J. Educ. Technol. High. Educ., vol. 14, no. 1, p. 1, Dec. 2017, doi: 10.1186/s41239-017-0046-1.

[12] F. Zhao, "Enhancing the quality of online higher education through measurement," Qual. Assur. Educ., vol. 11, no. 4, pp. 214-221, Dec. 2003, doi: 10.1108/09684880310501395.

[13] "Simple and Multiple Linear Regression," ResearchGate. https://www.researchgate.net/publication/326876947_Simple_and_M ultiple_Linear_Regression (accessed May 18, 2020).

[14] F. Diana-Rose, M. A. Zariyawati, K. Norazlina, M. N. Annuar, and O. Manisah, "Consumers' Purchasing Decision towards Food Products of Small and Medium Enterprises," vol. 6, no. 4, p. 8, 2016.

[15] H. Lin, "Knowledge sharing and firm innovation capability: an empirical study," Int. J. Manpow., vol. 28, no. 3/4, pp. 315-332, Jun. 2007, doi: 10.1108/01437720710755272. 